\title{
O Ativismo Católico: Bioética, Direitos Reprodutivos e Gênero
}

\author{
Lilian Sales ${ }^{1}$ (iD) 0000-0002-4169-1149 \\ 'Universidade Federal de São Paulo, Guarulhos, SP, Brasil. 07252-312
}

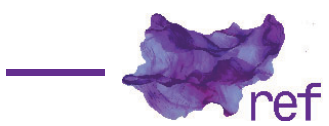

\begin{abstract}
Resumo: Neste artigo, acompanharemos o processo de formação do ativismo católico antidireitos sexuais e reprodutivos e antigênero na lgreja Católica, descrevendo alguns de seus momentos e características centrais. Retraçaremos as linhas da política institucional instituída pelo Vaticano que culminaram na explosão militante católica contrária a esses temas. Analisaremos desde a organização da ofensiva doutrinária e acadêmico-científica, marcada pela produção de concepções teológicas e pela sua defesa em termos não doutrinais, mas científicos, jurídicos e filosóficos por experts vinculados à Igreja Católica, até a organização da ofensiva pastoral, centrada na difusão das categorias antidireitos sexuais e reprodutivos e antigênero por meio de todo o aparato institucional da lgreja, desde seu topo até suas bases.
\end{abstract}

Palavras-chave: Igreja Católica, direitos sexuais e reprodutivos, bioética, gênero.

Catholic Activism: Bioethics, Reproductive Rights and Gender

Abstract: This article will follow the process of formation, in the Catholic Church, of an activism opposed to the sexual and reproductive rights and opposed to the-gender. We will retrace the lines of institutional policy instituted by the Vatican that culminated in a Catholic militant explosion against these themes. We will analyze from the organization of a scientific, academic and doctrinal offensive, until the organization of the pastoral offensive, centered on the diffusion of categories against sexual and reproductive rigths and against gender through the entire institutional apparatus of the Church. Keywords: Catholic Church, sexual and reproductive rights, bioethics, gender.

\section{Activismo católico: Bioética, Derechos Reproductivos y Género}

Resumen: Este artículo seguirá el proceso de formación, en la lglesia Católica, de un activismo anti-derechos sexuales y reproductivos y anti-género. Trazaremos las líneas de la política institucional instituida por el Vaticano que culminó en la explosión militante católica contra estos temas. Analizaremos desde la organización de una ofensiva científica, académica y doctrinal, hasta la organización de la ofensiva pastoral, centrada en la difusión de categorías anti-derechos sexuales y reproductivos y anti-género através de todo el aparato institucional de la Iglesia.

Palabras clave: Iglesia católica, derechos sexuales y reproductivos, bioética, género.

A ałuação de atores vinculados à Igreja Católica em controvérsias públicas relacionadas à bioética e aos direitos sexuais e reprodutivos, especialmente em temáticas relacionadas ao início da vida humana, foi notada no Brasil na última década. As tentativas de intervenção da CNBB (Congregação Nacional dos Bispos do Brasil) em ações julgadas pelo Supremo Tribunal Federal (STF) sobre esse tema, como a Ação Direta de Inconstitucionalidade (ADI) 3.510, que julgava a permissão do uso de células embrionárias em pesquisas científicas, e a ADPF 54, que julgou a possibilidade de interrupção da gestação em caso de anencefalia do feto, são dois exemplos do ativismo de atores católicos em questões de interesse público no país. Embora o posicionamento "em defesa da vida desde a concepção", defendido pela Conferência Episcopal, não tenha sido vitorioso em nenhum dos dois casos, a CNBB se fez presente nas duas ações, buscando interferir no resultado dos julgamentos, participando ativamente das ações e do debate público que as circundou. As 
duas controvérsias ${ }^{1}$ extravasaram as fronteiras da esfera judiciária onde ocorreu o julgamento da ação, entrando para o debate público e mobilizando atores em sua defesa ou em sua oposição, que acionaram estratégias na defesa de seus posicionamentos. ${ }^{2}$ As ações tratavam de um tema bastante caro ao catolicismo: o início da vida humana. E foi em defesa desta questão que seus agentes se levantaram com força argumentativa no debate público, inclusive jurídico e científico (Naara LUNA, 2010; 2013; Lilian SALES, 2014; 2015).

O ativismo católico sobre questões de bioética e reprodução humana, como o aborto, a reprodução assistida, o uso de células embrionárias em pesquisa, também foi observado na esfera política, além da judiciária. Representantes da Igreja Católica no parlamento têm se posicionando contrariamente às políticas públicas e aos projetos de lei que visassem à expansão dos direitos sexuais e reprodutivos, como em relação ao Plano Nacional de Direitos Humanos (PNDH), que previa a descriminalização do aborto e distribuição de materiais escolares abordando temas como diversidade sexual e de gênero (Maria das Dores MACHADO, 2015; 2018; Maria José ROSADO-NUNES, 2014).

O posicionamento de atores vinculados ao catolicismo contrariamente às temáticas de bioética, sexualidade e gênero não é uma exclusividade brasileira. Nas últimas décadas, o ativismo cristão contra os direitos sexuais e reprodutivos e contra as demandas por igualdade de gênero alcançou escala mundial. Desde meados dos anos 2000, a presença de atores vinculados à Igreja Católica em disputas públicas relacionadas ao início da vida e aos direitos sexuais e reprodutivos vem sendo notada em diversos países da América Latina e da Europa. Em muitos casos, essa presença envolveu a realização de mobilizações e de manifestações públicas contrárias às legislações e políticas em prol da expansão desses direitos (como do aborto, do casamento homossexual) e/ou a regulamentação de questões de bioética (reprodução assistida, uso de células embrionárias em pesquisas, eutanásia, entre outras).

Os enfrentamentos ocorreram quando legislações relativas a esses temas foram colocadas em discussão nos Estados Nacionais. ${ }^{3}$ Segundo Isacco Turinna (2012), a regulação dos nascimentos é um jogo biopolítico fundamental para as governanças modernas, sendo nas questões relacionadas à bioética e à reprodução humana que os conflitos entre a lgreja e os Estados são mais violentos. Phillipe Portier (2012), especialista do catolicismo na França, também reforça a colocação de Turinna, e aponta que o ativismo católico relativo às questões de bioética é acionado quando determinados temas são colocados em votação, como aqueles relativos à reprodução assistida, ao uso de células embrionárias em pesquisas científicas e à eutanásia.

O fenômeno do ativismo católico em relação aos direitos sexuais e reprodutivos e da bioética tem amplitude internacional e se manifesta nos momentos em que questões relativas a esses temas são colocadas em pauta nas esferas públicas nacionais: na esfera política, na esfera judiciária, na esfera educacional, entre outras. Embora os desdobramentos e os desfechos sejam específicos em cada caso e em cada país, observa-se a intervenção em bloco da lgreja Católica nessas questões. Essa atuação é decorrente da política institucional assumida pelo Vaticano desde meados dos anos 1990, que se reproduz em diversos países a partir da metade dos anos 2000, quando a alta hierarquia da Igreja inicia o combate sistemático a esses temas. Nosso intuito, nesse artigo, ${ }^{4}$ é seguir os passos do processo de organização e de formação de um ativismo católico antidireitos e antigênero, descrevendo alguns de seus momentos-chave. ${ }^{5}$

Em comum, além do ativismo em torno das questões de sexualidade e bioética, há o fato de as mobilizações e debates estarem organizados em torno de ideias e categorias que foram produzidas e disseminadas a partir do Vaticano, em seus textos doutrinais, entre meados dos anos 90 e meados dos anos 2000. Na primeira parte desse artigo, vamos retraçar os caminhos seguidos desde a criação dessas teorias e conceitos pela teologia católica até a explosão das

\footnotetext{
' O conceito de controvérsia vem sendo utilizado como paradigma analítico para compreender a formação e a configuração recente do espaço público brasileiro e o papel dos agenciamentos religiosos nesta construção. Tratase de um conceito a partir do qual temos observado o desenho de uma arena pública que emerge em situações de dissenso, confronto ou disputa. A inspiração para o uso desse conceito vem principalmente da leitura de autores franceses de linhagens relacionadas à Sociologia Pragmática, que colocam as situações de disputa como objetos de observação.

${ }^{2}$ As controvérsias públicas se reproduzem (ou se constituem) em múltiplas cenas: na mídia, em jornais e sites, na audiência pública que antecedeu as duas ações, na produção de documentários sobre essas temáticas (como a anencefalia), em marchas "em defesa da vida".

${ }^{3}$ Estudiosos do catolicismo europeu observaram as formas de atuação de atores católicos, especialmente das conferências episcopais e dos movimentos leigos, nos momentos em que as legislações referentes ao casamento homossexual (França, Portugal e Itália), a eutanásia (Bélgica), o aborto (Espanha), a reprodução assistida (ltália) e a diversidade sexual nos manuais escolares (França) foram colocadas em debate e votação nesses países, todos eles de tradição católica.

${ }^{4}$ Este trabalho é resultado do projeto "Religião, Direito e Secularismo: a reconfiguração do repertório cívico no Brasil contemporâneo" apoiado pela Fapesp (n²015/02497-5).

${ }^{5}$ Esse combate parte do Vaticano, mas não é consensual na lgreja Católica. Há vozes dissonantes entre sacerdotes e leigos que não se engajam nesse combate, ou mesmo que defendem posições divergentes em relação aos direitos sexuais e reprodutivos e à bioética. Esses não serão contemplados nesse artigo, que se limitará à ofensiva antidireitos travada a partir do Vaticano durante os papados de Karol Wojtyla e Joseph Ratzinger.
} 
mobilizações e manifestações protagonizadas por atores ligados à Igreja. Essas manifestações representam o auge de um longo percurso, que remonta desde a década de 1960, e que coloca a vida e a sua reprodução como centrais para a hierarquia católica. Ao longo desse período, e com mais intensidade a partir de meados dos anos 1990, o Vaticano empreendeu grandes esforços para a criação de doutrina e para a disseminação de suas ideias e posições sobre esses temas, agindo especialmente em três frentes, que serão observadas nesse artigo: a criação doutrinária, o esforço pastoral na difusão das posições teológicas, e o enfrentamento político quando esses temas entram em disputa nos cenários nacionais.

O enfrentamento público dessas questões é o resultado de um longo processo empreendido a partir da alta hierarquia católica nos papados de João Paulo Il e Bento XVI e que ganha contornos de política institucional do Vaticano. Tentaremos ao longo desse artigo retraçar os caminhos que culminaram na explosão militante católica observada desde 2007/2008.

Tomaremos como ponto de partida a produção doutrinária sobre bioética, gênero e sexualidade, a partir da análise das Encíclicas e de outros documentos oficiais do Magistério Católico, e a simultânea formação de uma expertise católica sobre esses temas, defensora do posicionamento teológico da Igreja a partir de termos e teorias acadêmico-científicos e jurídicos. Em seguida, trataremos do esforço pastoral dedicado à ampla disseminação das posições do Vaticano por todo o corpo institucional da lgreja Católica. Esse conjunto de ideias e estratégias criadas e disseminadas pelo Magistério da lgreja desde meados da década de 1990 compôs o instrumental necessário para a emergência das manifestações contrárias à expansão dos direitos sexuais e reprodutivos em diversos países de tradição católica a partir de meados dos anos 2000 .

\section{A ofensiva do Vaticano: contextualização}

Vários estudos apontam que o estopim da reação da Igreja Católica sobre as questões de bioética, gênero e reprodução humana foram as conferências onusianas realizadas nos anos 1990: a Conferência do Cairo (1994) e a Conferência de Pequim (1995). O Vaticano amargou importantes derrotas em seus posicionamentos relativos às políticas de controle da reprodução e aos direitos sexuais nessas duas conferências, que foram marcadas por intensos embates entre representantes do Vaticano e os Movimentos de Mulheres (Sonia CORREA, 2018; Sara GARBAGNOLI; Maxime PREARO, 2017), e dos quais as feministas saíram vitoriosas, obtendo o reconhecimento dos direitos sexuais e reprodutivos enquanto direitos humanos.

A derrota das posições defendidas pelo Vaticano é crucial para a consolidação do posicionamento católico sobre bioética, reprodução humana e gênero, e dá início a uma reação de enfrentamento às políticas de reconhecimento dos direitos reprodutivos e de bioética nos fóruns de debate internacional e nos Estados Nacionais. Embora vários estudiosos apontem o confronto entre o Vaticano e os movimentos de mulheres nas conferências da ONU, o detalhamento da ofensiva travada pela Igreja Católica desde o momento da sua derrota, e que culmina na consolidação de um ativismo católico contrário aos direitos sexuais e de gênero de caráter transnacional, ainda é pouco explorado. Buscaremos, aqui, acompanhar a articulação dessa ofensiva, que não foi realizada subitamente, mas gestada ao longo da década subsequente às conferências citadas.

O primeiro passo da ofensiva se faz no plano teológico, a partir da produção de textos doutrinais sobre bioética, sexualidade e reprodução, abordando temas como as novas tecnologias reprodutivas, o aborto, a eutanásia, o casamento homossexual, entre outros. Na verdade, os temas da sexualidade e da reprodução humana vinham ganhando centralidade na alta hierarquia católica desde a década de 1960, e a importância atribuída a eles se consolida durante o papado de João Paulo II e tem continuidade no papado de Bento XVI.

A produção doutrinária sobre esses temas se inicia com a Encíclica Humanae Vitae, de 1968 (PAULO VI, 2001), que aborda a reprodução e as formas de contracepção aceitas ou não pela Igreja Católica. Segundo Isacco Turina (2012), é nesse período que o controle dos nascimentos e da sexualidade foi se tornando cada vez mais central. Essa centralidade é constatada pelo volume de textos do Magistério Católico voltados especificamente para os temas da reprodução humana e da sexualidade, temas que anteriormente eram abordados com raridade, segundo Romain Carnac (2013). A partir da Encíclica Humanae Vitae, eles se tornam cada vez mais comuns. Essa encíclica estabelece os parâmetros da doutrina católica sobre o tema da procriação e também uma nova teologia sobre a sexualidade. Nela se condena o uso de métodos anticoncepcionais ditos "artificiais", como a camisinha e a pílula anticoncepcional (que havia sido descoberta recentemente).

Segundo Carnac (2013), Karol Wojtyla foi o teólogo responsável por organizar a moral sexual católica em um dispositivo doutrinário coerente. Ele foi o principal teórico do discurso católico sobre o comportamento sexual e a reprodução desde o final dos anos 1960 até o início de seu papado, nos anos 80 , sendo que a produção teológica sobre a sexualidade e sobre 
o papel da mulher se fortalece durante o seu longo papado, em escritos como na exortação apostólica Familiaris Consortio (JOÃO PAULO II, 1981), e na Mulieris Dignitatem (JOÃO PAULO II (1988), entre outras. Nesses escritos, a sexualidade está sempre restrita ao casamento, os métodos anticontraceptivos aceitos são apenas aqueles embasados na abstinência (classificados como naturais), e a homossexualidade é colocada como contrária à "lei natural", que remete à complementaridade entre os sexos.

Durante o papado de João Paulo II (1978 a 2005), o posicionamento doutrinal da lgreja Católica sobre o controle dos nascimentos e a sexualidade não se modifica significativamente, mantendo as posições presentes desde a Encíclica Humanae Vitae (1968). A novidade está em torná-las o foco da produção e da divulgação teológica do Vaticano. Ao longo do papado de Karol Wojtyla, a produção de textos sobre bioética, reprodução e sexualidade humana ganha volume e centralidade, constituindo-se no tema crucial das políticas institucionais do Vaticano, e tendo como um de seus principais defensores e entusiastas o representante máximo da Instituição: o Papa João Paulo II.

Todas essas temáticas, no âmbito do catolicismo, estão associadas às questões de família, sendo em geral tratadas conjuntamente em seus textos doutrinais. Dessa forma, data do mesmo período (as décadas de oitenta e início dos anos noventa), e por vezes dos mesmos escritos, a concepção da diferença e da complementaridade entre os sexos, sendo colocada como um dos fundamentos da "lei natural" por João Paulo II. Essa concepção recebe o estatuto de verdade da razão, e a sua divulgação é realizada por instâncias de difusão doutrinária do Vaticano. Nesse período, Wojtyla usa o termo "gênio feminino" em seus escritos, essencializando as características e o papel da mulher. ${ }^{6}$

Nota-se, pois, que os temas da reprodução, da sexualidade e da complementaridade entre os sexos já estavam presentes na teologia moral católica e vinham ganhando centralidade na década de oitenta, antecedendo as conferências da ONU do Cairo (1994) e de Pequim (1995). O posicionamento do Vaticano sobre esses temas foi intensamente defendido por seus representantes na Conferência de Pequim. Nessa Conferência, segundo Garbagnoli e Prearo (2017), o Vaticano se bate para tentar impedir o reconhecimento, pela ONU, dos direitos sexuais e reprodutivos enquanto direitos humanos. Inclusive, em 1995, no momento anterior à Conferência, João Paulo II (1995a) escreve a "Carta às mulheres", em que as concepções do "gênio feminino" e da "complementaridade entre os sexos" são reafirmadas. Entretanto, os esforços do Vaticano não foram suficientes para que ele obtivesse a vitória nas instâncias internacionais, sendo atendidas as demandas dos movimentos de mulheres pelo reconhecimento dos direitos reprodutivos.

Segundo Luciano Oliveira (2018), a primeira vitória do movimento de mulheres acontece no ano anterior, em 1994, na Conferência do Cairo sobre população e desenvolvimento. As interações e alianças entre diferentes grupos foram fundamentais para essa vitória, sendo destacada a aliança entre os movimentos de mulheres e grupos de neomalthusianos, ambos interessados em questões relacionadas à expansão dos direitos reprodutivos. Essa aliança culmina no reconhecimento do aborto como direito a ser exercido pelas mulheres e na inserção dos direitos sexuais e reprodutivos enquanto direitos humanos na Conferência do Cairo, que é reafirmada no ano seguinte, na Conferência de Pequim.

O reconhecimento desses direitos é a maior vitória dessa aliança, ocorrida no momento em que o Comitê Internacional da Conferência sobre População e Desenvolvimento no Cairo buscou implementar uma política incomum: uma política populacional permeada por direitos das mulheres. O Programa de Ação do Cairo representou um acordo efetivado entre feministas e os responsáveis pela Conferência, os neomalthusianos. Conforme explicam Dennis Hodgson e Susan Watkins (1997, p. 467), essa política populacional se une à do sistema de direitos sexuais e reprodutivos das feministas, e ambos os movimentos falam em termos de um "terreno comum": os neomalthusianos se comprometem a uma estratégia de equidade de gênero para alcançar a estabilização da população, e concordam programaticamente em suplementar as atividades de planejamento de atividades de saúde; e as feministas oferecem, por sua vez, apoio aos objetivos neomalthusianos, e esse apoio é fortemente circunscrito com a retórica dos direitos humanos em relação à escolha (HODGSON; WATKINS, 1997).

Essa vitória é sucedida e confirmada na Conferência Mundial sobre a Mulher, realizada em 1995, em Pequim. Nessa segunda conferência, o conceito de "gênero" começa a ser construído como o inimigo pela Igreja Católica, sendo que, ao longo dela, as militantes pró-aborto são classificadas como "feministas do gênero" pela militante norte-americana antiaborto Dale O'Leary, aliada do movimento católico Opus Dei (GARBAGNOLI; PREARO, 2017, p. 46; MACHADO, 2018). As autoras indicam que nesse momento se inicia a apropriação da categoria "gênero" pelos representantes do catolicismo, estando circunscrita a uma classificação atribuída a um grupo de feministas e inserida em um embate mais amplo, relativo ao papel da mulher e aos direitos sexuais

" Parte importante da doutrina católica sobre a "essência" do feminino e da complementaridade entre os sexos encontra-se na Encíclica Redemptoris Mater, de 1985, e também em outros escritos, como as já mencionadas Exortações Apostólicas Mulieris Dignitatem (1985) e Familiaris Consortio (1981). 
e reprodutivos. O uso do termo "gênero" entre os católicos era muito pontual e específico, estando associado aos papéis de cada sexo. Somente após essa conferência, como abordaremos mais adiante, que teólogos católicos se apropriam do termo, criando uma categoria que o utiliza, a "ideologia de gênero", para combater as políticas de expansão dos direitos sexuais.

As importantes vitórias dos movimentos de mulheres obtidas nas Conferências Internacionais da ONU no Cairo (1994) e em Pequim (1995) provocam uma reação institucional severa no Vaticano, que culmina na organização de uma ofensiva com dimensões internacionais relativas às questões de gênero, de sexualidade e de bioética. Organizaremos essa ofensiva em três eixos para facilitar a compreensão, embora todas elas estejam profundamente conectadas: a produção de textos doutrinais, a disseminação mundial das teorias e concepções e a formação de um ativismo católico contrário às temáticas de bioética, gênero e sexualidade.

\section{A reação do Vaticano: a ofensiva doutrinária}

A organização dessa ofensiva é iniciada no momento imediatamente posterior à Conferência do Cairo, a partir da elaboração de textos do Magistério Católico, como Carta às mulheres, escrita por João Paulo II (1995a). Essa Carta representa um dos primeiros movimentos dessa reação, que se intensifica após a Conferência de Pequim, com a publicação da Encíclica Evangeliun Vitae, ainda em 1995 (JOÃO PAULO II, 1995b). Ela é considerada o textochave que estabelece bases e direcionamentos do posicionamento do Vaticano sobre bioética, especialmente em temas relacionados ao início e ao fim da vida. A concepção de "cultura de morte" é cunhada nessa Encíclica para defender a disposição católica contrária a qualquer intervenção ou interrupção não "naturais" da vida humana, abrangendo temas como o aborto, a eutanásia e o uso de células embrionárias, a reprodução assistida, entre outras. Todos esses procedimentos fazem parte daquilo que a Evangelium Vitae classifica como "cultura de morte", e que servirá para a "defesa da vida desde a concepção até seu fim natural".

A Encíclica Evangelium Vitae é o primeiro e o principal texto no qual a posição do Vaticano sobre a temática da bioética emerge de forma organizada e sistematizada, em um só documento. Ela repercute de forma imediata nas Faculdades de Teologia, sendo analisada por especialistas da área de Teologia Moral, que passam a estudá-la e discuti-la em suas disciplinas, a publicar artigos em revistas de teologia e orientar dissertações e teses a seu respeito. Desde o momento de sua publicação, em 1995, e na década seguinte, um grande número de publicações na área de teologia moral, analisando diversos pontos dessa Encíclica, foi publicado. ${ }^{7}$

Entretanto, essa Encíclica não lança apenas as bases teológicas sobre os temas em questão; nela também se institui a Academia Pontifícia para a Vida, que, a partir de 1996, reúne cientistas e juristas que defendem as convicções doutrinárias da Igreja Católica sobre bioética e reprodução humana. Ela é responsável por produzir dados científicos e argumentos jurídicos e filosóficos que embasem os posicionamentos teológicos. O Vaticano, desde então, atribui características de elaborações acadêmicas para esses temas, justificando seus posicionamentos em termos jurídicos e científicos. Essa é uma segunda característica importante da ofensiva católica: características de discurso científico, tendo sido gestadas no interior de Institutos de bioética. Desde os anos 1990, a bioética se torna uma área de conhecimento que ganha atenção especial do Vaticano. Ela se torna o campo científico que respalda as posições do Vaticano e dos atores vinculados ao catolicismo nas disputas envolvendo o início ou o fim da vida humana.

O investimento na produção de categorias também se estende às questões de gênero, sistematizando doutrinariamente temáticas relativas à sexualidade e ao gênero. $O$ Vaticano organiza uma retórica antigênero que, de forma semelhante à noção de "cultura de morte", ganha os contornos de uma expertise. Segundo estudiosas do tema, o uso do termo "gênero" por teólogas católicas inicia-se ainda durante a Conferência de Pequim, como categoria de acusação a alguns grupos de mulheres, classificadas enquanto "feministas do gênero" (CORRÊA, 2018; MACHADO, 2018). Nesse momento, entretanto, o uso dessa categoria ainda é intuitivo, não estando sistematizado doutrinariamente ou embasado em discussões filosóficas e do direito, trabalho que será realizado pelos teólogos católicos, com o apoio de juristas, filósofos e cientistas, ao longo da década que sucede as conferências.

A categoria "gênero" volta a aparecer nos escritos de Joseph Ratzinger (2005), como uma forma de dessencialização das características biológicas relativas a cada um dos sexos; ela seria uma forma de corrupção das características essenciais dos sexos (Richard MISKOLCl; Maximiliano CAMPANA, 2017). A essencialização das características referentes a cada sexo não é nova na teologia moral católica, já estando presente nos escritos de Karol Wojtyla e possuindo grandes semelhanças com a concepção do "gênio feminino" e da "complementaridade entre

7 Realizamos levantamento dos artigos publicados em duas revistas teológicas editadas pela Universidade de Navarra (UNAV) e notamos o impacto e a disseminação quase imediata das concepções e ideias presentes nessa Encíclica a partir do grande volume de artigos e de teses de teologia moral sobre ela. A UNAV é uma Universidade Católica pertencente ao Opus Dei, e considerada pelos estudiosos do catolicismo na Europa como um dos polos de difusão das ideias católicas sobre bioética, gênero e reprodução. 
os sexos" forjada por ele. A ideia da "complementaridade entre os sexos" traz em seu bojo a concepção de que cada sexo apresenta a sua "essência", sendo ambos complementares. A partir das conferências da ONU, teólogos se apropriam e reformulam o conceito de "gênero", antes inexistente nos documentos do Magistério Católico, a partir das noções já presentes em sua teologia moral, especialmente nos escritos de Wojtyla. Nesse processo, criam uma categoria que questiona a propriedade do termo gênero, responsabilizada, segundo Ratzinger, pela "dessencialização" das características atribuídas a cada sexo, que posteriormente se tornou conhecida como "ideologia de gênero", e um "novo feminismo", contrário ao feminismo defendido pelas "feministas do gênero".

De forma semelhante aos escritos sobre bioética, os escritos abordando o gênero são primeiramente de ordem teológica. Uma das primeiras referências ao "gênero" é de 1997, em que Dale O'Leary (1997), representante católica ligada ao Opus Dei, presente nas reuniões do Cairo e de Pequim, lançou nos Estados Unidos o livro The Gender Agenda: Redefining Equality. Segundo a autora, o objetivo da publicação era discutir a "radicalização do feminismo" a partir das influências do pensamento marxista em acadêmicas feministas. Essas feministas eram classificadas pela autora, desde as conferências onusianas, como "feministas do gênero".

Data do mesmo ano a publicação do Sal da Terra... por Joseph Ratzinger (2005), em que ele se utiliza do termo "gênero". Nota-se, portanto, ainda nos anos 1990, que proeminentes teólogos católicos, ligados diretamente ao Vaticano e ao Papa João Paulo II, como Joseph Ratzinger, ${ }^{8}$ se apropriam dos termos "gênero" e "feminismo", dando início à reelaboração desses conceitos e atribuindo-lhes sentidos que estivessem de acordo com as suas convicções doutrinárias.

E em relação ao ativismo antigênero, um dos textos teológicos centrais, que inspira os demais, é a Encíclica Evangelium Vitae (EEV). Ela infunde a formulação de uma teoria sobre o gênero na Igreja Católica, e sugere a elaboração de um novo "feminismo". A proposta de se elaborar "um novo feminismo" é reveladora do principal inimigo estabelecido pelo Vaticano: os movimentos feministas, ou, na classificação nativa, "as feministas do gênero".

O "novo feminismo", formulado sobretudo por teólogas, muitas ligadas ao Opus Dei, como Jutta Burggraf (2001), reconhece homens e mulheres como iguais em direitos, responsabilidade e dignidade. Nenhum deles deve ser assumido como inferior ao outro. No casamento, a mulher não é uma escrava ou serva, mas sim uma companheira. A diferença entre os sexos, portanto, não corresponde ou justifica qualquer desigualdade. Nesse sentido, o novo feminismo defende causas históricas do movimento feminista. No entanto, faz um ponto de inflexão: de que somente se deve apoiar o movimento de emancipação das mulheres caso este não invista contra as diferenças entre os sexos. Nos termos de Burgraff, retomando os escritos de Karol Wojtyla, a igualdade entre os sexos não possui fundamentação na teologia católica, que enfatiza a diferença e a complementaridade entre os sexos.

Seu maior ponto de atrito com o feminismo é com aquele que reivindica a "igualdade entre os sexos" e não apenas a igualdade de direitos entre homens e mulheres. Do ponto de vista filosófico, sua principal adversária é Simone de Beauvoir. Para Burgraff, Beauvoir desvaloriza o que há de mais específico do feminino: a maternidade. Ser mãe é algo que apenas a mulher pode experienciar, é apenas em um corpo feminino em que a criação divina se materializa. A maternidade seria, assim, o núcleo do que chama de "maternidade espiritual", que seria um dom de todas as mulheres, até mesmo daquelas que não são mães, pois em todas as mulheres a predisposição para a maternidade implicaria um dom de solidariedade, o desenvolvimento de uma maior sensibilidade para a necessidade dos outros e, assim, uma capacidade privilegiada para o cuidado (BURGGRAF, 2001, p. 35-37). No entanto, Burgraff salienta que essas qualidades devem ser valorizadas não apenas no âmbito doméstico, pois seriam também indispensáveis para a justiça. O amor materno seria, assim, um atributo tipicamente feminino que contribui para fortalecer os laços entre justiça e solidariedade, entre a moralidade universal e o vínculo de amor e cuidado.

Em suma, esse é o argumento estruturante do "Novo Feminismo" católico. É feminista porque reconhece as opressões históricas a que a mulher esteve e está submetida, e é novo na medida em que busca criar um lugar intermediário entre o feminismo que luta pelos direitos políticos e sociais das mulheres, e aquele que depreciaria o 'gênio feminino' e não acata a "complementaridade entre os sexos".

As "feministas do gênero", desde as conferências onusianas, são associadas à "cultura de morte", pela defesa dos direitos reprodutivos, em especial do direito ao aborto. Além disso, também são associadas à homossexualidade, devido à demanda dos direitos sexuais que foi incorporada na plataforma da ONU a partir da Conferência de População e Desenvolvimento do Cairo, em 1994. Conforme a posição do Vaticano fracassa em relação a essas duas temáticas, conforma-se um inimigo em comum: o movimento feminista, ou "as feministas do gênero". Desde então, um novo processo de embate aos direitos sexuais e reprodutivos é iniciado.

${ }^{8}$ Joseph Ratzinger dirigia a Congregação para a Doutrina da Fé nesse período. 
A EEV e as publicações da década de 1990 estão centradas na justificação teológica contrária à noção de "gênero" e à "cultura de morte". A elaboração jurídica e/ou científica dessas noções tem início logo em seguida.

\section{A ofensiva acadêmico-científica}

O posicionamento teológico católico sobre a bioética, a reprodução e a sexualidade é elaborado como um discurso de expertise, utilizando termos, elementos e discussões acadêmicocientíficas em suas formulações. Para isso, a ofensiva científica realizada pelo Vaticano é fundamental: a produção doutrinária do Vaticano é acompanhada da formação de uma expertise sobre esses temas, que é formalmente criada na citada Encíclica Evangelium Vitae.

A bioética se torna o campo de conhecimento que engendra temáticas de enfrentamento à expansão dos direitos sexuais e reprodutivo e com isso ganha centralidade na hierarquia Católica. Nesse aspecto, uma das primeiras ações do Vaticano, após a criação da Pontifícia Academia para a vida, foi a criação de Institutos de Bioética em todas as Universidades Pontifícias na Europa e na América Latina (Gabriela IRRAZÁBAL, 2010). Esses especialistas se tornam os responsáveis pelo tom acadêmico atribuído às elaborações teológicas. Os Institutos científicos criados nas universidades católicas ganham a incumbência de alocar e formar especialistas que tiveram papel central no tom acadêmico incorporado ao discurso teológico do Vaticano. O Instituto Universitário Campo Biomédico, de Roma, e o Instituto de Bioética da Universidade de Navarra são dois casos que se tornam referência na formulação do discurso acadêmicocientífico da Igreja Católica sobre bioética, reprodução humana e sexualidade.

A defesa dos posicionamentos e convicções católicas por cientistas e médicos, que se utilizam dos termos e da metodologia científica, não é propriamente uma novidade na lgreja Católica. Autoras já demonstraram que desde o enfrentamento com o cientificismo ocorrido na França no século XIX a Igreja Católica, por meio de médicos e cientistas, defende seus posicionamentos utilizando a linguagem científica (Elisabeth CLAVERIE, 2009; Ruth HARRIS, 2001). Consideramos que a novidade se encontre na escolha de um campo específico de enfrentamento pelo Vaticano a partir do início dos anos 2000 , que se refere às questões de bioética e de sexualidade.

Observamos que, ao longo de uma década, o investimento da lgreja Católica na ofensiva doutrinária e na ofensiva científica foi paulatinamente formulado, sendo que, em 2003, essa reelaboração doutrinária, iniciada em 1995, está amadurecida e sistematizada. Esse é o ano da publicação do Léxico dos termos ambíguos e controversos sobre a vida, a família e as questões éticas pelo Pontifício Conselho da Família (2003), no formato de um dicionário enciclopédico, traduzido e lançado em nove línguas (Céline BÉRAUD, 2013). Ao longo de dez anos, os teólogos católicos, em conjunto com aliados acadêmicos, cientistas e juristas, se dedicaram a estudar, debater, elaborar e organizar a doutrina da Igreja Católica sobre as questões de bioética, sexualidade e gênero, que ganha em 2003 um formato final. No Lexicon (CONSELHO PONTIFÍCIO PARA A FAMÍLIA, 2003), o argumento "anticultura de morte" e o argumento "antigênero" da lgreja Católica estão organizados e caracterizados como um discurso secular, científico e feminista, que reforça a concepção da complementaridade entre os sexos" (GARBAGNOLI; PREARO, 2017, p. 58).

$O$ instrumental da Igreja Católica antidireitos reprodutivos e antigênero está definido na forma de um discurso de expertise, que irá subsidiar as manifestações e mobilizações no campo do ativismo autonomeado pró-vida e pró-família, de pauta ampla contra temas relacionados à sexualidade e à reprodução da vida: aborto, união homoafetiva, educação sexual em escolas, eutanásia, uso de células embrionárias, reprodução assistida. Todos esses verbetes são encontrados no Lexicon, que começa a circular amplamente pelo catolicismo: pelas faculdades de teologia, pelos institutos de bioética, pelas comissões e pastorais de família, e foi prontamente traduzido para o francês, o espanhol, o inglês e o português, atingindo uma ampla gama de católicos. ${ }^{9}$

O acionamento do repertório jurídico e científico produzido ao longo da década posterior às conferências da ONU foi observado nas disputas sobre bioética e sexualidade que eclodiram no final dos anos 2000. A utilização desse repertório foi notada por estudiosos do catolicismo na Europa e na América Latina. Juan Vaggione (2017) classifica essa atitude como uma forma de "secularismo estratégico" empreendido pela Igreja Católica, reportando-se ao uso de argumentos seculares no combate à expansão dos direitos sexuais e reprodutivos por representantes do catolicismo. A Igreja, por meio de suas instituições, faria uso do repertório dos direitos humanos, como a noção de liberdade religiosa, como uma forma de contenção à expansão desses direitos.

Já Portier (2012) destaca que a presença da Igreja Católica nas decisões e normas formuladas pelo Estado francês se faz por meio do uso dos termos da razão pública. A Igreja

\footnotetext{
9 O Lexicon é uma publicação do Pontifício Concilio para a Família, sendo o Cardeal Antonio Trujillo o responsável pela sua primeira edição. O Cardeal Trujillo é colombiano, e muito rapidamente o Lexicon ganhou uma tradução para o castelhano, que foi lançada na América Latina.
} 
Católica, na França, elabora estratégias de intervenção na esfera de deliberação pública que operam em duas arenas: a sociedade civil e a sociedade estatal. No espaço social, também chamado de sociedade civil, o autor visualiza dois tipos de intervenção, realizadas por meio de dois modos de ação: um modo de ação discursivo, embasado em posições oficiais do Vaticano, em que aplica termos da razão pública, como de discursos sobre os direitos do homem e a dignidade humana. O outro, modo de ação popular, responsável pela organização da difusão de suas concepções por meio de campanhas, blogs, colóquios, em busca da formação de opinião de acordo com os fins de sua doutrina. A segunda forma de intervenção ocorreria no espaço estatal, dirigida diretamente à classe políitico-jurídica, onde os termos da razão pública são predominantes.

Essa estratégia de atuação de atores e instituições católicas se repete em várias nações, e aponta para uma atuação comum e em bloco estabelecida a partir da mais alta hierarquia católica: o Vaticano. Além disso, indica o interesse central atribuído a essa temática por seus altos representantes: João Paulo II e Bento XVI. O ativismo antigênero e anticultura de morte ganha contornos de política institucional do Vaticano nesses dois papados. ${ }^{10}$

\section{A ofensiva pastoral: a difusão de categorias e teorias}

Houve uma década de preparação de uma caixa de ferramentas doutrinárias e conceituais contrárias às questões de gênero, reprodução e bioética que antecedeu a explosão militante observada a partir da segunda metade dos anos 2000. A produção de doutrina e de teorias acadêmicas foi o primeiro passo para a produção desse ativismo. O segundo passo foi a disseminação das ideias e posições católicas entre todas as instâncias do catolicismo; esse foi o segundo movimento da ofensiva católica: a ofensiva pastoral na divulgação das suas posições e concepções por todo o seu corpo institucional. Localizamos três meios de disseminação das ideias católicas sobre esses temas: as conferências episcopais nacionais, os institutos de bioética e/ou de estudos da família ligados às universidades católicas (mencionados no item anterior) e os movimentos leigos, como a Renovação Carismática Católica e o movimento Neocatecumenal. ${ }^{11}$

Gabagnoli e Prearo (2017) estudaram a dispersão das concepções católicas antigênero na França e na ltália, países que presenciaram grandes manifestações contrárias ao casamento homossexual protagonizadas pela lgreja Católica no início dos anos 2010, e afirmam que: "antes de ser uma mobilização de rua a ofensiva antigênero foi uma mobilização para a divulgação de saberes" (p. 78). Acrescentaríamos que, ainda antes, foi uma mobilização para a produção de saberes, conforme observado nos itens anteriores. Os autores mapearam a disseminação do saber antigênero entre grupos e movimentos católicos, destacando a circulação de pregadores entre países e a estratégia de se realizar oficinas e conferências para difundir as concepções católicas sobre gênero e sexualidade entre os leigos. Nos trabalhos de Béraud (2013) e de Portier (2012), estudiosos do catolicismo na França, também identificaram a importância dos grupos carismáticos na disseminação das concepções católicas sobre bioética.

Essas obras assinalam a intensa centralidade e dedicação de três grupos da Igreja Católica na difusão das concepções sobre sexualidade, reprodução e bioética no universo católico europeu: a Renovação Carismática Católica, o movimento Neocatecumenal e o Opus Dei. As Conferências Episcopais Nacionais também desempenham importante papel na defesa desses saberes, conforme identificado na obra coletiva coordenada por Alfonso Pérez-Agote e Karel Dobbelaere (2015). Os autores apontam a presença e a defesa das concepções sobre bioética, sexualidade e gênero nas conferências episcopais de cinco países de tradição católica: França, Itália, Bélgica, Espanha e Portugal. Em cada um desses países houve mobilizações, de diferentes tipos e medidas, com a participação das conferências episcopais contrariamente à aprovação de legislações relativas à bioética ou aos direitos sexuais e reprodutivos: casamento homossexual (França e Itália), eutanásia (Bélgica).

O terceiro elemento fundamental na dispersão das noções do Vaticano sobre gênero, sexualidade e bioética foram as universidades católicas e seus institutos de bioética e de "estudos da família", sobretudo aquelas ligadas ao Opus Dei que, além de formularem as teorias e conceitos sobre esses tópicos, também têm um papel fundamental como centros difusores dessas ideias. Teólogos, profissionais em bioética, direito, filosofia, estudos da família, são formados a partir dos conhecimentos forjados pela intelectualidade católica nesses centros, e passam a disseminar essas ideias. A Universidade de Navarra, por exemplo, possui uma dimensão internacionalizada, formando teólogos, especialistas em bioética, filósofos e juristas dentro das concepções doutrinárias católicas. Esses especialistas tornam-se reprodutores dessas noções

\footnotetext{
${ }^{10}$ Aqui nos referimos à centralidade e ao direcionamento institucional do Vaticano sobre esses temas nesse período. Porém, importa mencionar que, apesar disso, a lgreja Católica não é um bloco único, existindo movimentos e atores divergentes e dissonantes em relação à posição da alta hierarquia.

${ }^{11}$ A identificação de atores, instituições e movimentos de destaque na difusão das posições do Vaticano foi obtida a partir de pesquisa bibliográfica e também pelo acompanhamento das controvérsias públicas relacionadas ao início da vida no Brasil, nas quais mapeamos autores e argumentos centrais nessas disputas.
} 
em outros espaços, desde o universo religioso católico, por meio de teólogos que difundem essas ideias em seus países de origem, mas também de juristas, médicos, biomédicos, entre outros profissionais que passam por seus cursos de formação e institutos de pesquisa.

Esses caminhos, entretanto, não são traçados separadamente. Pelo contrário, as alianças e conexões entre teólogos, sacerdotes, cientistas, juristas e demais profissionais são fundamentais para a defesa das convicções católicas a partir das gramáticas em jogo nas arenas em que as disputas se desenrolam: jurídica, científica, dos direitos humanos, entre outras, e também para a dispersão desses saberes entre os leigos, e não apenas entre sacerdotes.

\section{A chegada e a dispersão dos saberes na América Latina e no Brasil}

Observamos similaridades entre a presença e a mobilização dos saberes católicos sobre bioética, sexualidade e gênero em questões de interesse público na Europa e no Brasil. As concepções e teorias forjadas pelo Vaticano foram acionadas em controvérsias públicas relacionadas ao início da vida envolvendo atores católicos no país, como em duas ações julgadas pelo STF (ADI 3.510 e ADPF 54), nas quais os conhecimentos sobre a "bioética católica" são utilizados por sacerdotes e bispos, mas também por cientistas e juristas.

O final dos anos 2000 é um momento particularmente importante na dispersão desses conhecimentos no Brasil e na América Latina. Em 2008, foi julgada a ADI 3.510, que analisou a permissão do uso de células-tronco embrionárias em pesquisas científicas. A CNBB participou ativamente dessa ação, sendo aceita como amicus curiae no processo e constituindo advogado "em defesa da vida dos embriões criocongelados". Essa ação ultrapassou a esfera judiciária e entrou para o debate público nacional, no qual os valores e ideais instituídos pela teologia moral católica sobre bioética, contrários à "cultura de morte", foram replicados nas múltiplas cenas que constituíram essa controvérsia: na audiência pública que antecedeu o julgamento, nas mídias, em publicações e artigos, em programas de televisão e nas redes sociais.

Nesse mesmo período, várias obras sobre bioética são publicadas por editoras católicas, como a Editora Vozes, cujo diretor-presidente era Frei Antônio Moser, professor de teologia moral e um dos principais especialistas brasileiros nos princípios de bioética professados pela lgreja Católica, sendo ele próprio autor de livros e artigos sobre essa temática.

Frei Moser ocupava um lugar de destaque na difusão (e também na defesa) da "bioética católica". Ele lecionava em Universidades e Institutos de Bioética Católicos, publicava livros e artigos científicos sobre essa temática, participava das comissões de Bioética da CNBB e ocupava posto de destaque em uma das principais editoras católicas brasileiras - a Editora Vozes. Além disso, também desempenhava um importante trabalho pastoral, publicando artigos em sites católicos de grande divulgação - como o site da CNBB e o site da Comunidade Carismática Canção Nova. Frei Moser também possuía um programa televisivo na mesma rede, no qual os temas relacionados à bioética eram frequentemente debatidos e era convidado recorrentemente para entrevistas e programas televisivos que tratassem de temas da bioética. As publicações de Frei Moser eram sempre acompanhadas de um minicurrículo:

Frei Antônio Moser é Diretor Presidente da Editora Vozes, professor de Teologia Moral e Bioética no Instituto Teológico Franciscano em Petrópolis, membro do Conselho Administrativo da Diocese de Petrópolis, Pároco da Igreja de Santa Clara, membro da Comissão de Bioética da CNBB, Presidente da Comissão de Bioética da Universidade Católica de Petrópolis, além de conferencista no Brasil e no exterior. Escreveu 25 livros e inúmeros artigos científicos para revistas nacionais e internacionais. Além disso, desenvolve intensa atividade pastoral, sendo um dos grandes especialistas brasileiros em Pastoral Familiar e Bioética.

Ele foi ator central na defesa e na difusão dos conhecimentos sobre bioética no país, dominava os bens simbólicos importantes no universo acadêmico, o que o legitimava para defender as convicções da Igreja Católica nas controvérsias públicas, como no caso da ADI 3.510, em que escreveu artigos, participou de programas e de entrevistas colocando-se contrariamente ao uso de células embrionárias em pesquisas.

Além disso, Frei Moser é agente importante na divulgação desses conhecimentos entre os leigos católicos devido à sua grande inserção nos meios de comunicação, católicos ou não, e devido ao vínculo com a Comunidade Canção Nova, ligada à Renovação Carismática Católica, movimento importante na defesa do posicionamento antigênero e antidireitos sexuais e reprodutivos.

Apesar de seu papel central, Frei Moser não era o único defensor das concepções católicas sobre a "cultura de vida"; elas já eram recorrentes entre os bispos brasileiros no final da década de 2000. A realização de um levantamento em artigos e notícias publicados no site da CNBB apontou a repetição do argumento "em defesa da vida desde a concepção até seu fim natural" nessas publicações. ${ }^{12}$ Houve uma grande frequência de artigos de bispos no site

12 Organizamos e sistematizamos os artigos publicados no site da Conferência Episcopal no período em que essa controvérsia esteve ativa. Identificamos os principais autores e os argumentos recorrentes. Utilizamos o programa de análise de dados qualitativos Atlas TI para sistematizar o grande volume de informações. 
da CNBB que se utilizavam desse argumento, demonstrando já terem conhecimento das teorias e concepções elaboradas pela teologia moral sobre bioética e reprodução humana (embora em diferentes graus e medidas). Dessa forma, parte do bispado brasileiro é agente reprodutor dessas teorias.

Além disso, nesse mesmo ano, 2008, foi lançada a Campanha da Fraternidade, que tinha como tema "Fraternidade e Defesa da Vida", voltando-se para temas sobre o início e o fim da vida, como aborto e eutanásia, englobando discussões sobre o estatuto do embrião. Tratavase, na verdade, de um apanhado sobre os principais pontos da "Bioética Católica", de acordo com os conceitos e teorias desenvolvidos anteriormente pela Teologia Moral e com os contornos científicos elaborados nos Institutos de Bioética Católicos. Em 2008, 5 anos após a publicação do Lexicon, quando as categorias e ideias sobre esse tema já estavam desenvolvidas, é lançada uma Campanha que amplifica a difusão dessas ideias no Brasil.

As Campanhas da Fraternidade são anualmente lançadas pela CNBB, abordando um tema específico a cada ano, que é recolocado em todo ritual celebrado durante o período da quaresma. As CF possuem um texto de referência, chamado de texto-base e, a partir dele, são elaboradas pregações, cânticos e passagens bíblicas que serão repetidas durante os rituais católicos em todas as paróquias brasileiras, especialmente nas missas. Os católicos que eventual ou constantemente participem desses rituais entram em contato com as ideias postuladas pelas campanhas.

No texto-base da CF de 2008 (CNBB, 2008), ${ }^{13}$ o uso de células embrionárias em pesquisa e o aborto são dois itens de um mesmo capítulo, denominado "A vida não nascida". Ambos os temas são parte de uma mesma discussão, remetendo-se aos chamados "crimes contra a vida humana", no caso, a vida dos embriões e fetos. As ideias presentes no texto-base da CF possuem ampla circulação entre o público católico. O texto-base é apresentado aos párocos, possuindo também uma versão em slides, como uma aula em que os sacerdotes aprendem as ideias que deverão ser trabalhadas em suas paróquias. Ambos são repletos de dados, tabelas, gráficos que buscam evidenciar a existência da vida desde a fecundação até o seu fim natural. Além disso, o texto usa os referenciais científicos na estruturação da escrita, usando citações, fontes e referências bibliográficas e conceitos de áreas de conhecimento relacionadas à bioética.

Constatamos, pois, que em 2008 os saberes sobre bioética, especialmente aqueles relacionados à "defesa da vida", e contrários à "cultura de morte", já estavam disseminados entre os bispos da CNBB e eram defendidos por especialistas: médicos, biomédicos. O lançamento da Campanha da Fraternidade pela CNBB, os múltiplos artigos de bispos no site da Congregação, a participação na ação julgada pelo STF são evidências disso. Restava, pois, a disseminação dessas concepções entre os leigos católicos. A Campanha da Fraternidade é uma estratégia central para a difusão mais ampla dessas ideias, fazendo com que elas se enraízem entre as bases do catolicismo.

As concepções centrais sobre bioética estão presentes no texto-base, e são colocadas em uma linguagem menos cientificista, de forma a se tornarem acessíveis a um grupo maior: primeiro, para os sacerdotes, padres e bispos responsáveis pela condução da campanha em suas paróquias; em seguida, para os leigos em geral, frequentadores de missas, novenas, entre outros rituais. Nesta segunda etapa, imagens, como cartazes e vídeos, e hinos são produzidos com base nessas concepções, possuindo uma circulação e penetração bem mais ampla que o texto-base.

Ocorre, assim, a circulação destas concepções, elaboradas pela intelectualidade católica, por todos os níveis da Instituição. A grande penetração e a reprodução da Campanha em todas as paróquias brasileiras demonstram como estas ideias são amplamente disseminadas: as categorias elaboradas pela teologia moral e cientificamente organizadas são veiculadas para o público em geral.

A "defesa da vida" está presente em todos os materiais da campanha: no hino oficial, nas imagens e pregações. O hino possui também um videoclipe que o associa às imagens, sendo que em mais de uma passagem quando a palavra "vida" ou as palavras "escolha da vida" são mencionadas surge a imagem de uma mulher grávida ou, ainda mais emblemático, a de um feto. Essa associação traz em si a concepção de que o feto é vida. Esse é um exemplo de como as concepções científica e filosoficamente elaboradas por uma expertise vinculada ao catolicismo são amplamente veiculadas de forma imagética e musical.

A CF 2008 foi central para a extensa difusão dos saberes sobre bioética, especialmente relacionados ao início e ao fim da vida, entre o público católico brasileiro. Já os saberes sobre sexualidade e gênero surgem alguns anos depois, no início dos anos 2010. Novamente, a intervenção das conferências episcopais e dos movimentos leigos é importante, expressada de forma recorrente por meio da categoria "ideologia de gênero".

13 O texto-base da Campanha da Fraternidade de 2008 pode ser consultado em https://campanhas.cnbb.org.br/ wp-content/uploads/2015/03/textobase1.pdf. 
As primeiras referências ao termo "ideologia de gênero" às quais tivemos acesso no Brasil datam de 2011, e estão presentes em artigos e reportagens veiculados pelo Canal Canção Nova, ligado ao movimento Renovação Carismática Católica, e no site da CNBB. Essas primeiras publicações trazem referências ao texto produzido pela Conferência Episcopal do Peru, em 2008, denominado "A ideologia de gênero: seus perigos e alcances", que explica o que seria a "ideologia de gênero" (CONFERÊNCIA EPISCOPAL PERUANA, 2008). ${ }^{14}$ Esse texto explicativo, escrito originalmente em espanhol, está traduzido para o português no site da Canção Nova, datando de 2011 . Nesse mesmo ano, ocorre a publicação, nesse mesmo site, de uma longa reportagem chamada "Ideologia de Gênero: saiba mais e conheça riscos para a sociedade" (Leandro MEIRA, 201 1), que também se apoia no texto produzido pela Conferência Episcopal do Peru.

Miskolci e Campana (2017) situam essas referências no Brasil e na América Latina ainda mais anteriormente, afirmando que o termo aparece na Conferência do CELAM (Conselho Episcopal Latino-Americano) de 2007, realizada na cidade de Aparecida do Norte (SP-Brasil). $O$ termo é abordado no "Documento de Aparecida" produzido a partir dessa conferência.

Além dos documentos produzidos pelas Conferências e Conselhos Episcopais, fundamentais para a difusão das ideias sobre gênero e sexualidade entre os sacerdotes latinoamericanos, autores também apontam a centralidade da obra do argentino Jorge Scala, advogado e professor de bioética, lançada em 2010: Ideologia de gênero: El género como heramienta de poder, que foi publicada no Brasil, em 2011, com o seguinte título: Ideologia de Gênero: neototalitarismo e morte da família (MISKOLCl; CAMPANA, 2017; MACHADO, 2018). Essa obra é referência frequente nos artigos e reportagens que abordam a "ideologia de gênero" no país.

Vários elementos apontam ser o início dessa década o momento crucial de disseminação da concepção sobre a ideologia de gênero pela América Latina, e, conforme notado nos casos europeus, o papel das conferências e conselhos episcopais e do movimento leigo Renovação Carismática, principalmente por meio da Comunidade Canção Nova e seus meios de comunicação, é central na transmissão das ideias católicas antigênero. Para nos determos em um só exemplo, o levantamento realizado no site da "Canção Nova" apontou 6.650 referências ao termo "ideologia de gênero" desde o ano de 2011.

O termo "ideologia de gênero" talvez tenha sido a categoria forjada pelo Magistério Católico que mais sucesso e penetração obteve no Brasil. Nos últimos anos, ela ultrapassou o universo do catolicismo, fazendo também parte das demandas antidireitos sexuais e reprodutivos defendidas por grupos evangélicos (LUNA, 2018; MACHADO, 2018) e também nos movimentos da "nova direita" (Álex KALIL, 2018). Apesar da sua grande repercussão, é importante colocála em perspectiva, situá-la como parte de um esforço conjunto travado desde o Vaticano contrariamente às questões de bioética, sexualidade e gênero, e à expansão dos direitos sexuais e reprodutivos.

\section{Consideraçōes finais}

Ao longo desse artigo, demonstramos o surgimento e o fortalecimento de uma ofensiva da Igreja Católica em relação às questões de gênero, sexualidade e bioética que extrapola as fronteiras nacionais. A grande batalha travada pela alta hierarquia católica desde meados da década de 90, que parte do Vaticano e se reproduz nas conferências episcopais nacionais, diz respeito a esses temas. O Magistério Católico investe em uma ofensiva teológica e acadêmicocientífica, produzindo um grande número de textos oficiais, nos quais embasa suas concepções de teologia moral em gramáticas dos direitos dos homens e das ciências. O Lexicon, publicado pelo Pontifício Conselho para a Família, é o exemplo mais bem organizado dessa ofensiva teológica e científica.

O investimento na organização desse ativismo antidireitos sexuais e reprodutivos e antigênero parte da alta hierarquia da Igreja: o Vaticano, sendo forjado durante os papados de João Paulo II e de Bento XVI e intensamente apoiado por eles. Esses dois Papas estiveram pessoalmente envolvidos na formulação do posicionamento institucional da lgreja, sendo autores de importante produção teológica envolvendo essas questões. João Paulo II, desde antes de se tornar Papa, já escrevia textos sobre a moral sexual católica e sobre os papéis de cada sexo que, posteriormente, na década de 1980, foram organizados na forma de uma "teologia do corpo". Paralelamente, o posicionamento do Vaticano foi preparado, com o apoio desses pontífices, em termos de uma expertise, caracterizado por um discurso secular e defendido por especialistas - juristas, cientistas, médicos, filósofos, além de teólogos. Isso ocorre a partir de meados da década de 1990, após as conferências da ONU no Cairo e em Pequim, e a partir da publicação da Encíclica Evangelium Vitae por João Paulo II, na qual a Pontifícia Academia para a Vida é instituída.

${ }^{14}$ Essa expressão já estava presente como verbete no Lexicon desde sua primeira versão, de 2003. 
Dessa forma, ao longo desses dois papados, que somam três décadas, as questões de bioética, sexualidade e reprodução foram ganhando centralidade na alta hierarquia da Igreja e tornado-se cada vez mais o foco das preocupações institucionais do Vaticano, que prepara uma potente reação de enfrentamento a essas temáticas, ramificada e reproduzida nos países de tradição católica.

A instituição católica mobiliza toda a sua estrutura institucional na dispersão de suas concepções e posicionamentos. Ela possui um grande dispositivo territorial formado por uma ampla rede de dioceses e paróquias, está organizada nacionalmente em Comissões Episcopais, possui meios financeiros, Universidades e Institutos de pesquisa, e, além disso, conta com o apoio de movimentos leigos de grande capilaridade e poder de influência, como a Renovação Carismática Católica e o Opus Dei. Todas essas características tornam o processo de disseminação de suas concepções bastante eficiente. Por meio dessas estratégias, grupos de defensores de valores morais são organizados e se constituem como um reservatório de militantes, que se mobilizam quando as temáticas são colocadas em pautas nos cenários nacionais. A estrutura hierárquica, mas ao mesmo tempo capilar, do catolicismo é fundamental na produção e divulgação de suas concepções.

Além da formação de defensores morais, ocorre também a formação de especialistas, que defendem os valores do catolicismo em termos de razão pública, utilizando-se da linguagem em jogo nas contendas públicas: dos direitos, das ciências, da bioética, entre outros. Acionam, pois, um "secularismo estratégico", segundo a expressão cunhada por Vaggione (2017).

Assim, o ativismo católico contrário a essas temáticas não surgiu subitamente, mas foi paulatinamente organizado e disseminado pela Igreja Católica a partir do seu centro de poder político, formando suas bases, mas também uma intelectualidade composta principalmente por teólogos, especialistas em bioética, juristas e cientistas. Múltiplas instâncias institucionais da lgreja foram mobilizadas nesse processo: faculdades e institutos de pesquisa, conferências episcopais e movimentos leigos. Há uma temporalidade entre a fabricação do discurso católico contrário à bioética e aos direitos sexuais e reprodutivos e a mobilização do ativismo católico contrário às legislações e ações referentes ao aborto, à educação sexual nas escolas, ao gênero, ao casamento homossexual, à eutanásia, entre outros.

As mobilizações observadas em vários países e em múltiplas esferas (política, jurídica, educacional, entre outras) caracterizam o ativismo católico antigênero e antidireitos sexuais e reprodutivos, e são decorrentes da política institucional adotada pelo Vaticano, que se estabelece há mais de quinze anos no centro dos dispositivos de autoridade da Igreja Católica, em encíclicas, conferências episcopais, disseminando-se entre dioceses e paróquias. As bases para esse ativismo já se encontram formuladas, difundidas e enraizadas no momento em que as questões eclodem nos Estados. No Brasil, as ações julgadas pela Suprema Corte foram marcadas pela presença da CNBB e de especialistas na "Bioética Católica".

Dessa maneira, observa-se que a lgreja Católica produz as categorias, produz a expertise para defendê-las em termos não doutrinais, mas sim científicos e jurídicos, e coloca essas categorias em circulação, utilizando-se de todo o seu aparato institucional na disseminação dessas concepções. Quando essas questões são colocadas em pauta nas agendas nacionais, a Igreja Católica já está preparada para dar início às mobilizações.

A invenção da cultura de morte e da ideologia de gênero agrega os católicos em torno do posicionamento contrário a essas questões, tornando possíveis mobilizações contrárias a elas globalmente.

\section{Agradecimento}

Esse artigo é resultado do trabalho de pesquisa desenvolvido junto ao Projeto Temático "Religião, Direito e Secularismo" (n. 2015/02497-5), financiado pela Fapesp, a quem agradecemos o apoio.

\section{Referências}

BÉRAUD, Céline. "Les catholiques contre le genre. Le episode des manueles de SVT". In: ROCHEFORT, Florence; SANNA, Maria Eleonora (Orgs.). Normes Religieuses et Genre. Paris: Armand Colin/Recherches, 2013. p. 109-121.

BURGGRAF, Jutta. Hacia un nuevo feminismo para el Siglo XXI. San Jose: Promesa, 2001.

CARNAC, Romain. "S'adapter pour mieux résister: la théologie de la sexualité de Jean-Paul II". In: ROCHEFORT, Florence; SANNA, Maria Eleonora (Orgs.). Normes Religieuses et Genre. Paris: Armand Colin/Recherches, 2013. p. 97-108.

CLAVERIE, Elisabeth. "Parcours politique d'une apparition: Le cas de Lourdes". In: Archives des Sciences Sociales des Religions, Paris, v. 145, 2009. 
CNBB. "Campanha da Fraternidade 2008". CNBB, 2008. Disponível em https://campanhas.cnbb. org.br/wp-content/uploads/2015/03/textobase1.pdf. Acesso em 15/01/2018.

CONFERÊNCIA EPISCOPAL PERUANA. "A ideologia do gênero: seus perigos e alcances". Canção Nova, 2008. Disponível em https://img.cancaonova.com/noticias/pdf/281960 IdeologiaDeGenero_PerigosEAlcances_ConferenciaEpiscopalPeruana.pdf.

CORRÊA, Sonia. "A 'política do gênero': um comentário genealógico". Cadernos Pagu, Campinas, n. 53,2018 . e185301.

CONSELHO PONTIFÍCIO PARA A FAMÍLIA. Lexicon: termos ambíguos e discutidos sobre família, vida e questões éticas. Rio de Janeiro: Edições CNBB, 2003.

DOBBELAERE, Karel; PÉREZ-AGOTE, Alfonso. The Intimate: Laws about Life, Death and the Family in So-called Catholic Countries. Leuven: Leuven University Press, 2015.

GARBAGNOLI, Sara; PREARO, Maxime. La croisade anti-genre. Du Vatican aux manifs pour tous. Paris: Editions Textual, 2017.

HARRIS, Ruth. Lourdes. Paris: Jean Claude Lattes, 2001.

HODGSON, Dennis; WATKINS, Susan. "Feminists and neo-Malthusians: Past and present alliances". Population and Development Review, v. 23, n. 3, p. 469-523, September 1997.

IRRAZÁBAL, Gabriela. "Bioética y catolicismo. Dificultades en torno a la constitución de una identidad colectiva". Religião \& Sociedade, Rio de Janeiro, v. 30, n. 1, p. 101-116, 2010.

JOÃO PAULO II. Exortação Apostólica Familiaris Consortio. São Paulo: Paulinas, 1981.

JOÃO PAULO II. Mulieris Dignitatem. Lettera Apostolica sulla dignità e vocazione della donna in occasione dell'anno mariano. São Paulo: Paulinas, 1988.

JOÃO PAULO II. Carta às mulheres. São Paulo: Paulus, 1995a.

JOÃO PAULO II. Carta Encíclica Evangelium Vitae (Sobre o valor e a inviolabilidade da vida humana). São Paulo: Loyola, 1995b.

KALIL, Álex. "Do religioso ao civil: Reconfigurações da Ideologia de Gênero no Espaço Público". Revista Pensata, Guarulhos, v. 7, p. 21-41, 2018.

LUNA, Naara. "Embriões no Supremo: Ética, Religião e Ciência no Tribunal". Teoria e Sociedade, Porto Alegre, n. 18, p. 168-203, 2010.

LUNA, Naara. "O direito à vida no contexto do aborto e da pesquisa com células-tronco embrionárias: disputas de agentes e valores religiosos em um Estado laico". Religião \& Sociedade, Rio de Janeiro, v. 1, n. 33, p. 71-97, 2013.

LUNA, Naara. "O julgamento no Supremo do aborto de anencéfalo - ADPF 54: uma etnografia da religião no espaço público". Horizontes Antropológicos, Porto Alegre, n. 52, p. 165-197, 2018.

MACHADO, Maria das Dores. "Religião e política no Brasil contemporâneo: uma análise de pentecostais e carismáticos católicos". Religião \& Sociedade, Rio de Janeiro, v. 35, n. 2, p. 4572, 2015.

MACHADO, Maria das Dores. "O discurso cristão sobre a ideologia de gênero". Revista Estudos Feministas, Florianópolis, v. 26, n. 2, p. 447-463, 2018.

MEIRA, Leandro. "Ideologia de Gênero: saiba mais e conheça riscos para a sociedade". Canção Nova, 2011. Disponível em https://noticias.cancaonova.com/brasil/ideologia-de-genero-saibamais-e-conheca-riscos-para-a-sociedadel.

MISKOLCI, Richard; CAMPANA, Maximiliano. 'Ideologia de gênero': notas para a genealogia de um pânico moral contemporâneo". Sociedade e Estado, v. 32, n. 3, p. 725-747, 2017.

O'LEARY, Dale. The Gender Agenda: Redefining Equality. Lafayette: Vital Issues Press, 1997.

OLIVEIRA, Luciano. "A mobilização e a contramobilização em torno do aborto - os enfrentamentos entre feministas e representantes do Vaticano na Conferência do Cairo de 1994". Pensata, 2018. Disponível em https://periodicos.unifesp.br/index.php/pensata/article/view/10096. 
PAULO VI. Carta Encíclica Humanae Vitae. São Paulo: Editora Paulinas, 2001.

PORTIER, Philippe. Droit, éthique et religion. De l'âge théologique à l'âge bioéthique. Paris: Bruyant, 2012.

RATZINGER, Joseph. O Sal da Terra: o Cristianismo e a Igreja Católica no século XXI: um diálogo com Peter Seewald. Rio de Janeiro: Imago Editora, 2005.

ROSADO-NUNES, Maria José. "Gênero: uma questão incômoda para as religiões". In: SOUZA, Sandra Duarte; DOS SANTOS, Naira Pinheiro. Estudos Feministas e Religião: Tendências e Debates. Curitiba: Prismas; Universidade Metodista, 2014. p. 129-147.

SALES, Lilian. "A controvérsia em torno da liberação de pesquisas com células-tronco embrionárias no Brasil: posições e argumentos dos representantes da lgreja Católica". Revista de Antropologia, São Paulo, v. 57, n. 1, p. 179-213, 2014.

SALES, Lilian. "'Em defesa da vida humana': moralidades em disputa em duas audiências públicas do STF". Religião \& Sociedade, Rio de Janeiro, v. 35, p. 143-164, 2015.

TURINNA, Isacco. "Le Magistere post-conciliare face au Biopouvoir”. In: BÉRAUD, Céline; GUGELOT Frédéric; SAINT MARTIN, Isabelle (Orgs.). Catholicisme en tension. Paris: Les Éditions de l'EHESS, 2012.

VAGGIONE, Juan. "La Iglesia Católica frente a la política sexual". Cadernos Pagu, n. 50, 2017. e175001.

Lilian Sales (lilian.sales@unifesp.br) é Professora Adjunta de Antropologia na Universidade Federal de São Paulo. Mestre e Doutora em Antropologia Social pela USP.

\section{COMO CITAR ESTE ARTICO DE ACORDO COM AS NORMAS DA REVISTA}

SALES, Lilian. "O Ativismo Católico: Bioética, Direitos Reprodutivos e Gênero". Revista Estudos Feministas, Florianópolis, v. 29, n. 3, e71678, 2021.

\section{CONTRIBUIÇĀO DE AUTORIA}

Não se aplica.

\section{FINANCIAMENTO}

Pesquisa integrada ao Projeto Temático "Religião, Direito e Secularismo" (n. 2015/02497-5), financiado pela Fapesp.

\section{CONSENTIMENTO DE USO DE IMAGEM}

Não se aplica.

\section{APROVAÇÃo DE COMITÊ DE ÉTICA EM PESQUISA}

Não se aplica.

\section{CONFLITO DE INTERESSES}

Não se aplica.

\section{LICENÇA DE USO}

Este artigo está licenciado sob a Licença Creative Commons CC-BY 4.0 International. Com essa licença você pode compartilhar, adaptar, criar para qualquer fim, desde que atribua a autoria da obra.

\section{HISTÓRICO}

